\title{
Climate Influence on the Expansion and Tree-Ring Growth of Pinus nigra L. at High Altitude in the Central Apennines
}

\author{
Alma Piermattei ${ }^{*}$, Matteo Garbarino, Francesco Renzaglia and Carlo Urbinati
}

\author{
Department of Agriculture, Food and Environmental Sciences (D3A), Università Politecnica delle Marche, Ancona, Italy
}

\begin{abstract}
Scattered expansion of European black pine (Pinus nigra Arnold) has been observed above the current timberline in the central Apennines. We aimed to detect possible common pattern of structure and growth dynamics of pine regeneration in treeline sites. Over 700 black pine samples growing above the timberline were sampled at four sites in the limestone Apennines of Marche and Abruzzo regions. For each tree we measured basal stem diameter, total height and annual height increments; a wooden core was extracted from the stem near the ground for cambial age determination and detection of intra-annual density fluctuations (IADF). We used multivariate analysis to assess patterns of the main tree structural attributes and dendrochronological analysis for age structure and growth dynamics. Expansion of European black pine started about 35 years ago featuring similar germination peaks, tree structure and growth patterns in all the sites. IADF have similar frequencies and peaks and occur in mid-late summer. These similar patterns occur at all sites besides the local differences and grazing histories suggesting the presence of an overall climate driver.
\end{abstract}

Keywords: Climate change, European black pine, IADF, central Apennines, spatial patterns, timberline.

\section{INTRODUCTION}

In the central Apennines the timberline is usually composed by Fagus sylvatica L. forests located between 1500-1800 m a.s.l. At other sites extensive black pine plantations, created for slope-erosion control, form the new anthropogenic timberlines.

Several studies proved that the upward shift of beech forests in the central Apennines is a very slow or blocked process. However a consistent natural expansion of black pine has been documented above its altitudinal range of 800-1500 $\mathrm{m}$ a.s.l. This advancement is a complex process started over 35 years ago and controlled by synergic factors such as grazing pressure, climate, topography, seed availability, dispersion and germination efficiency [1]. In this research we aimed i) to detect possible common patterns of pine expansion process in the four sites, ii) to date the process and iii) to assess the role of climate.

Tree-ring and climate relationships are not easily detected with short tree-ring series, so we used the presence of intraannual density fluctuations (IADF) to assess possible climate influences $[2,3]$. These are significant alterations of cambial activity and useful indicators of tree adaptation to changing environmental conditions.

\section{MATERIAL AND METHODS}

\subsection{Study Area}

In the central Apennines we selected four study areas above the timberline (Table 1): at Mt. Acuto (ACU) this is a

*Address correspondence to this author at the Department of Agriculture, Food and Environmental Sciences (D3A), Università Politecnica delle Marche, Ancona, Italy; Tel: +39 071220 4274; Fax: +39 071220 4988; Emails: alma.piermattei@univpm.it, a-piermattei@libero.it coppiced beech forest and a residual black pine plantation is located on the same slope at about $300 \mathrm{~m}$ a.s.l. below the treeline at $1400 \mathrm{~m}$ a.s.l. At Mt. Vettore (VET) the timberline is mainly composed by extensive black pines plantations (50-60 years old) with few residual patches of the original beech forest. At Mt. San Franco (SFR) it is very similar to VET but with more recent plantations (35-50 yrs). At Mt. Sirente (SIR) the beech timberline is at much lower altitude from the karst plateau where the pine expansion is occurring. The field campaign was carried in 2005-2006 at ACU, 20072009 at VET, and in 2012 at SFR and SIR sites.

\subsection{Sampling Design and Data Analysis}

In each site all pine trees encountered between the timberline and the mountain top were mapped with a GPS device and sampled: 72 at ACU, 181 VET, 254 SFR and 151 SIR. For each tree we recorded the following parameters: tree vigor with class 1 (not damaged) to 5 (dead), root collar diameter, total tree height, crown shape, length of stem internodes and needle age. For age determination and treering analysis we also extracted one basal core with a Pressler borer from all individuals having a stem diameter $\geq 4 \mathrm{~cm}$. Tree-ring width measurements at $0.01 \mathrm{~mm}$ accuracy were provided by LINTAB and WinTSAP (Rinntech). We sampled and measured 429 cores (150 VET, 68 ACU, 112 SFR and 99 SIR).

To explore the correlation structure of the eight variables of tree structural attributes and to highlight underlying differences between the four sites, we applied a principal component analysis (PCA) using the PC-ORD 6 statistical package. The statistical significance of the ordination analysis was tested by the Monte Carlo permutation method based on 10000 runs with randomized data. 
Table 1. Summary statistics and main physiographic characteristics of the four study sites. For mean diameter and height the min and max values are reported in brackets

\begin{tabular}{|c|c|c|c|c|}
\hline & $\operatorname{Acuto}(\mathrm{ACU})$ & Vettore (VET) & San Franco (SFR) & Sirente (SIR) \\
\hline Latitude & $43^{\circ} 27^{\prime} \mathrm{N}$ & $42^{\circ} 81^{\prime} \mathrm{N}$ & $42^{\circ} 45^{\prime} \mathrm{N}$ & $42^{\circ} 15^{\prime} \mathrm{N}$ \\
\hline Peak elevation & $1668 \mathrm{~m}$ (a.s.1.) & $2476 \mathrm{~m}$ (a.s.1.) & $2132 \mathrm{~m}$ (a.s.1.) & $2348 \mathrm{~m}$ (a.s.1.) \\
\hline Aspect & $\mathrm{S}-\mathrm{SE}$ & $\mathrm{N}-\mathrm{NW}$ & W - SW & W - SW \\
\hline Main forest type & Beech coppice & Black pine plantation & Black pine plantation & No forest on karst plateau \\
\hline Mean diameter & $6 \mathrm{~cm}(2-10 \mathrm{~cm})$ & $9 \mathrm{~cm}(0.6-34 \mathrm{~cm})$ & $7.50 \mathrm{~cm}(0.5-44 \mathrm{~cm})$ & $12.5 \mathrm{~cm}(0.5-54 \mathrm{~cm})$ \\
\hline Mean height & $0.9 \mathrm{~m}(0.3-1.7 \mathrm{~m})$ & $1.5 \mathrm{~m}(0.10-7.5 \mathrm{~m})$ & $1.20 \mathrm{~m}(0.15-5.7 \mathrm{~m})$ & $1.95 \mathrm{~m}(0.10-8.4 \mathrm{~m})$ \\
\hline
\end{tabular}

Using a stereo microscope for each tree-ring series we recorded intra-annual density fluctuations (IADF). The frequency of IADF per years (F), was first calculated as the ratio [4]:

$F=N / n$

where $\mathrm{N}$ is the number of trees in which the IADF were present, and $\mathrm{n}$ is the number of observed trees. Since changing the samples depth can generate a bias in the variance of the frequency series an adjusted IADF frequency has been computed:

$f=F n^{0.5}$

where $f$ is the stabilized IADF frequency.

\section{RESULTS}

\subsection{Trees Structural Attributes and Age}

Most black pine trees are located between 1700 and 1800 $\mathrm{m}$ a.s.l., but some reach higher elevations at VET $(2000 \mathrm{~m}$ a.s.1.) and SIR (2155 $\mathrm{m}$ a.s.l.). The cambial age frequency distribution reveals that the pine recruitment started in the mid 1970's at SFR, SIR and VET and a few years later at ACU. At all sites the germination trends have normal distribution with main peak frequencies between 1992-2002, at SFR these are shifted forward (1998-2003).

The PCA on pine structural attributes revealed a high within sites variability, however the short distance in the ordinal environment between their centroids suggested minor differences between them. This is confirmed also by the high overlay of their convex hulls (Fig. 1). Very similar are SIR and VET with larger and slightly older saplings. SFR has a different pattern due to the abundance of younger trees. The needle age is positively related to tree vigor and both variables are totally uncorrelated to tree size. The first two principal components were significant $(\mathrm{p}<0.001$, Monte Carlo test) and accounted for a cumulative $67.1 \%$ of the overall variance.

\subsection{Distribution of Intra-Annual Density Fluctuations}

All the detected IADF are earlywood-type cells in the latewood band, near the tree-ring external borders, revealing that cambial activity first decreased or stopped during late summer drought and then recovered during late summer and early autumn. Distribution curves are unimodal except for SIR, with maximum peaks in 2003 for VET and SFR and 2004 for ACU and SIR (Fig. 2). The year 2003, has been among the warmest ones of the last centuries across Europe.

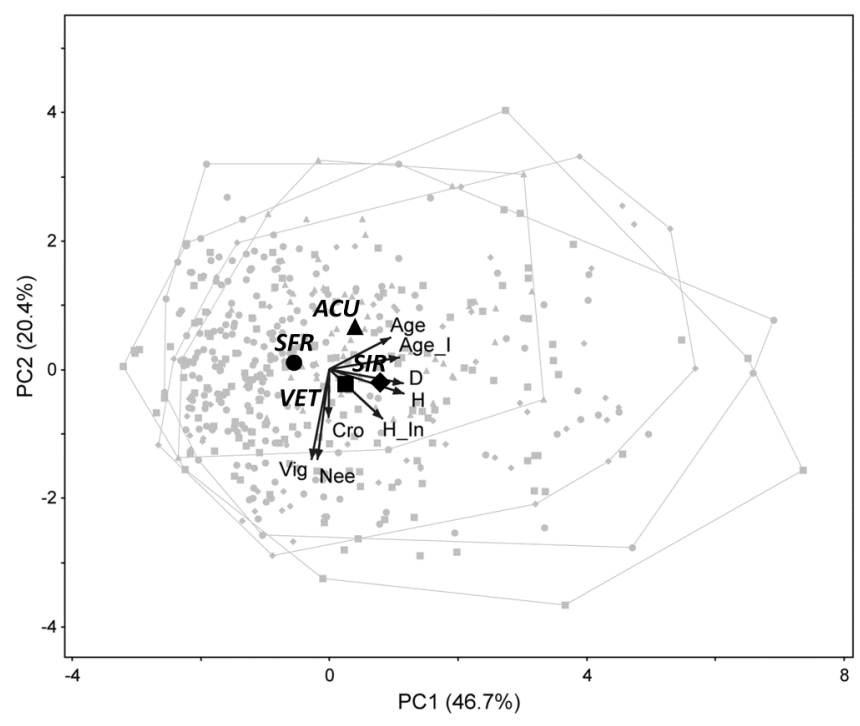

Fig. (1). Principal component analysis (PCA) performed on 468 trees surveyed at four treeline sites of the central Apennines. Full line arrows represent tree descriptors (D: diameter at root collar; $\mathrm{H}$ : tree height; H_In: mean length of internodes; Age: cambial age by increment cores; Age_I: estimated age by number of internodes; Cro: crown shape; Vig: tree vigor; Nee: number of years of permanence of needles on the branch stem). Grey dots are sampled trees (triangles: Acuto - ACU, circles: San Franco - SFR, squares: Vettore - VET; diamond: Sirente - SIR), black dots are the centroids of all the trees belonging to the same site. Grey polylines are convex hulls indicating the maximum surface area occupied by trees belonging to the same site.

\section{DISCUSSION}

The expansion of black pine above the current timberline in the central Apennines is a spontaneous process but linked to the presence of pine plantations. Pine upward expansion, even in these two new sites, confirmed to be a synchronic wave with peaks occurring between 1996 and 2000 and decreasing trend in following years [1]. The site features and 


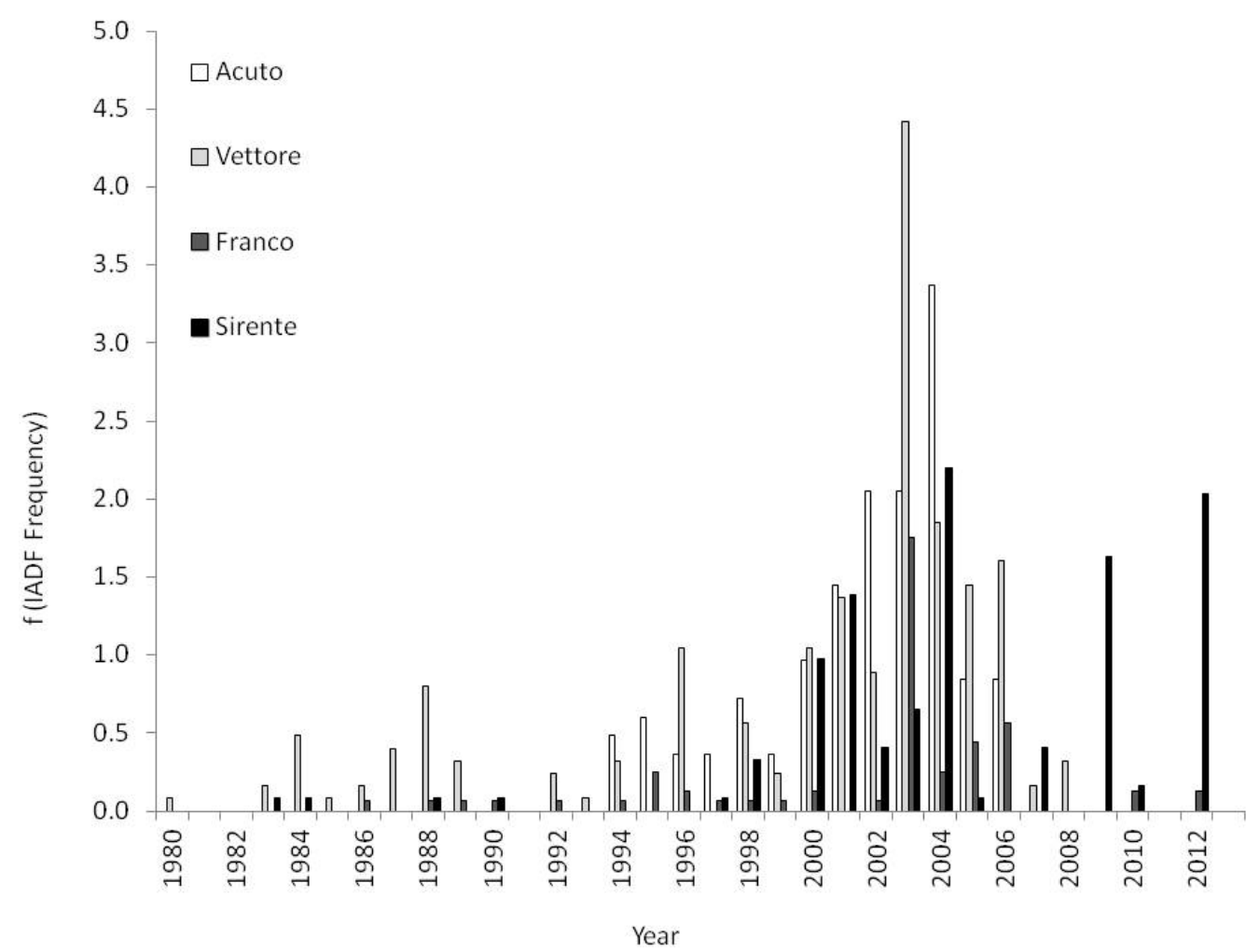

Fig. (2). Frequency distribution of intra-annual density fluctuations (IADFs). On the $y$-axis the "f" is the stabilized IADF frequency (f $=$ $\mathrm{Fn}^{0.5} ; \mathrm{F}=\mathrm{N} / \mathrm{n}$; where $\mathrm{N}=$ number of trees with fluctuations and $\mathrm{n}$ is the total number of samples).

grazing pressure are different in the four sites suggesting the presence of a climatic driver. Indeed the preliminary results of the PCA show a strong overall similarity of structural and growth attributes of pine trees due to the overlay of the four sites convex hulls. The within-site variability, more related to topographic and land use variables, is large and will be an important aspect to analyze in order to discriminate the pine expansion spatial patterns. Crossdating of tree-ring series is very difficult due to young ages of pines and the presence of numerous local noise factors. IADFs increased frequency can be interpreted as the effect of an adaptive strategy of black pine to mid-late summer drought. IADFs decreasing trend in some of the sites is biased by the diachronic sampling. More samples and further analyses are programmed for this research, but there are sufficient traits for envisaging the occurrence of a global driver, that besides local factors, can affect the pine expansion process at treeline in the central Apennines.

\section{CONFLICT OF INTEREST}

The authors confirm that this article content has no conflict of interest.

\section{ACKNOWLEDGEMENTS}

The authors wish to thank the Monti Sibillini National Park, the Gran Sasso and Monti della Laga National Park and the Velino-Sirente Regional Park for sampling permission. Marco Altieri for field and laboratory work.

\section{REFERENCES}

[1] Piermattei A, Renzaglia F, Urbinati C. Recent expansion of Pinus nigra Arn. above the timberline in the central Apennines, Italy. Ann Forest Sci 2012; 69(4): 509-17.

[2] Rigling A, Braker O, Schneiter G, Schweingruber F. Intra-annual tree-ring parameters indicating differences in drought stress of Pinus sylvestris forests within the Erico-Pinion in the Valais (Switzerland). Plant Ecol 2002; 163: 105-21.

[3] Vieira J, Campelo F, Nabais C. Age-dependent responses of treering growth and intra-annual density fluctuations of Pinus pinaster to Mediterranean climate. Trees 2009; 23(2): 257-65.

[4] Osborn TJ, Briffa KR, Jones PD. Adjusting variance for samplesize in tree-ring chronologies and other regional mean time series. Dendrochronologia 1997; 15: 1-10. 